\title{
PORTUGUESE AGRICULTURE AND ITS ROLE IN MULTIFUNCTIONAL RURAL DEVELOPMENT
}

\author{
Maria Raquel Ventura-Lucas ${ }^{a}$, Carlos Marques ${ }^{a}$, Maria de Belém Martins ${ }^{b}$ \& Rui Fragoso ${ }^{b}$ \\ ${ }^{a}$ CEFAGE-Centro de Estudos e Formação Avançada em Gestão - University of Évora, Portugal \\ ${ }^{b}$ CEFAGE-Centro de Estudos e Formação Avançada em Gestão - University of Algarve, Portugal \\ ${ }^{c} I C A A M$ - Instituto de Ciências Agrárias e Ambientais Mediterrânicas - University of Évora, Portugal
}

Abstract: ????

Key words: ?????

\section{Introduction}

As in Europe, agriculture in Portugal is supposed to fulfill a multiplicity of roles. It should contribute to supply Portuguese population with quality and safe food, to be viable in a global, competitive, dynamic and aggressive market, to preserve precious cultural landscapes across country through sustainable land management, to assist rural areas to be attractive and feasible and to support employment and social cohesion. Nevertheless, adjustments are expected to adapt to new environmental conditions, mainly climate change, to minimize weaknesses, to hold new opportunities and face new challenges. Otherwise, increases on human desertification, rural areas abandonment and consequent negative effects on territory are predictable.

The EU Common Agricultural Policy (CAP) intends to answer the agriculture's sustainability questions by enhancing the competitiveness of the agricultural sector, ensuring sufficient and secure food supply, preserving the environment and the countryside while providing for a fair standard of living for the agricultural community (EU, 2009).

In the actual context, Portuguese agriculture faces two main challenges that need to be balanced in the next years: food safety and environmental safety. It is imperative to know how to produce enough products to increase substantially the present volume of food supply and it is important to find ways to achieve productivity gains and increase UAA (Utilized Agricultural Area) in order to fight climate changes and promote sustainability of rural landscapes, natural resources and biodiversity. National interests should include struggle the abandonment of rural areas, valuate the territorial occupation and halt losses of biodiversity, achieve the auto-provisioning level of food supply, decrease external dependence of food by increasing export/import rates, define and implement priority actions to protect or sustain biodiversity, sustain farm structure diversity and match it with productive orientations appropriated at demographic, environmental and structural scale.

Following sections aims to demonstrate the ability or inability of Portuguese agriculture to respond to changing economic conditions as well as societal expectations and demands. The main question is to know how the CAP's evolutions through a policy with a double emphasis - on market orientation and competitiveness and on sustainability - can be strong enough to improve the development of Portuguese rural areas supporting farmers' income and environmental sustainability.

\section{Portuguese current situation and past trends}

This section follows closely EU rural development report structure to characterize rural development situation and past trends in Portugal. Two major aspects should be underlined: first, in Portuguese territory there is a sharp contrast in the location of predominantly rural, intermediate rural and predominantly urban areas according to OECD classification. All predominantly urban areas (NUTS III) are close to the sea and no predominantly rural areas (NUTS III) are found in the seaside. Hence, in this characterization we will refer as rural areas in Portugal to predominantly rural areas of OECD and we are at the same time speaking of inner areas of Portugal. Secondly, all Portuguese NUTS II regions combine seaside areas and large inner areas. Consequently, data for NUTS II averages these areas and so also averages urban and rural areas. To characterize rural areas of Portugal this data is useless and inadequate. Concluding, we will 
speak of rural areas as predominantly rural areas of OECD and use only NUTS III data to characterize those areas in Portugal.

\subsection{Importance of rural areas}

In Portugal, rural areas represented $69.7 \%$ of the territory and $21 \%$ of the population in 2006 . EU averages are $51.1 \%$ to $55.5 \%$ to territory and $14.7 \%$ to $36.1 \%$ of population ${ }^{1}$.

Traditionally, rural areas have low and declining population densities. Portuguese predominantly rural areas follow that pattern. Population is concentrated in the areas close to the sea and decreases rapidly as we move to inner areas. Average population density is 35 inhabitants $/ \mathrm{km}^{2}$ and there is a tendency to decline. These indicators contrast with increasing population densities of predominantly urban areas, reaching an average value of 697 inhabitants $/ \mathrm{km}^{2}$ in 2006.

Economic activities in these predominantly rural areas account for $16.7 \%$ of national Gross Value Added (GVA) and $20.7 \%$ of employment. Hence, rural areas in Portugal are particularly important in terms of territory and indicators per capita are much less far from average values then per territorial units.

\subsection{Socio-economic situation in rural areas}

Portuguese rural areas have, proportionally, less people below 14 and between 14 and 64 and more people above 65 years old than urban areas. Production per capita ${ }^{2}$ in rural areas is estimated in $60 \%$ (and compares with $88 \%$ for urban areas) of EU average. Hence, production levels are low in EU standards and there is a large gap between rural and urban areas. There is almost no change in this economic development indicator for rural areas and a small decrease for urban areas (-4\%) from 1999 to 2005.

Gross Value Added (GVA) of rural areas makes $7.6 \%$ of total value. Average change in the structure of the Portuguese economy from 2000 to 2006 is characterized by a decrease in the primary and secondary sectors' economic relevance of 1 and $3.3 \%$, respectively, and an increase of $4.3 \%$ in tertiary sector. Rural areas follow this general pattern with a $3.4 \%$ decrease of primary's sector GVA contribution to economic activity and an increase of $4.4 \%$, for the tertiary sector.

Employment in primary sector still represents $29.6 \%$ in rural areas of Portugal in 2006. However, in the period of 2000 to 2006 changes in rural areas' employment in primary, secondary and tertiary sectors of $-0.4 \%,-3.1 \%$ and $4 \%$ have been lower than their average values of $-0.8 \%,-4.2 \%$ and $5 \%$, respectively, indicating lower rates of adjustment, economic activity and opportunities. However, unemployment is lower in rural than in urban areas $(7.3$ and $9.3 \%$, respectively, in 2007) and change of unemployment rates are slower in rural than in urban areas (2.6 and 4.8\%, respectively).

\subsection{Agriculture}

Agriculture, forestry and hunting in 2006 employed around 589 thousand persons in Portugal representing $11.5 \%$ of total employment. The sector added value was estimated in 3400 thousand $€$ and represented $2.5 \%$ of GDP. The relative importance of primary sector is declining in Portugal following EU trend. In terms of employment its share declined $0.7 \%$ between 2000 and 2006 (1.2\% for EU-27) and 0.2 with respect to added value ( $0.6 \%$ for EU-27).

Agricultural area used in Portugal was 3.47 million hectares in 2007, with $31 \%$ utilised for arable crops, $51.3 \%$ for permanent pastures and $17.2 \%$ for permanent crops.

Farms numbered 275 thousand, of which $3.6 \%$ had more than 50 and $72.6 \%$ less than 5 hectares. Average farm size was 12.6 hectares, which is also the average size of farm in EU-27. In economic size ${ }^{3}$, however, Portuguese average value of 6.6 European Size Units (ESU) is far from the EU27 average of 11.3 . Only $0.8 \%$ farms have economic potential for more than $100 \mathrm{ESU}$ and more than half of the farms $(57.5 \%)$ have less than 2 ESU. Around 93.5 thousand very small farms that could be considered important in semisubsistence activities have less than 1 ESU (potential for GVA per year less than $1200 €$ ) and represent $34 \%$ of total number of farms.

Family farming based on the farmer or household fulltime job represents a large part of the labour force in agriculture that was estimated in 338 thousand annual work units in 2007. Around $11 \%$ of farmers had basic or full training in agriculture in 2005. In Portugal the proportion of "young" farmers is very low. In 2007, farmers with less than 35 years represented $3 \%$ of the farmers with more than 55 years. This means that Portugal has 1 "young" farmer for each 33 farmers of more than 55 years old. This is the lowest percentage among EU-27 and European average is $11 \%$.

Labour productivity in Portuguese agriculture is $48 \%$ of EU-27 average value (12 $089 €$ ) per $\mathrm{AWU}^{4}$. Gross Fixed Capital Formation in Portugal was estimated in 762 million $€$ in 2007 which represents $35.6 \%$ of GVA and is lower than EU-27 average ratio value (37.4\%).

\subsection{Food Industry}

The food industry makes an important contribution to economic activity. In Portugal, food industry accounted for 3132 million €in 2007 representing $2.4 \%$ of total GVA. This contribution increased at a rate of $1.4 \%$ between 2000 and 2006.

Investment in the food industry represents $25.9 \%$ of GVA and was estimated in 811.5 million $€$ in 2007 . The rate of investment decreased (-0.4\%) between 2000 and 2006. This industrial sub-sector employed around 110 thousand persons or $2.1 \%$ of total employment in 2007. Employment in food industry has also decreased at a rate of $-0.3 \%$ in the same period.

\footnotetext{
1 Depending on group of EU countries considered (EU-12, UE-15 and EU-27).

2 Evaluated by GDP in p.p.s. per capita and compared to average value of EU-27 $=100$.
} 
Labour productivity in the sub-sector as increased at an estimated rate of $1.7 \%$. In 2007 , labour productivity was around 28.5 thousand $€$ per person employed.

\subsection{Forestry}

Forest available for wood supply in Portugal covers about 2009 thousand hectares. Forest productivity was estimated in $6.8 \mathrm{~m}^{3} /$ tear /ha. Labour productivity is around 51.8 thousand $€$ per person employed, very close to average EU value of 51.5 (EU-15). Investment in the forestry sector in Portugal was estimated in 86.2 million $€$ in 2005 representing 13.6 of the sector GVA.

\subsection{Environment}

Agriculture and forestry have a fundamental role in preserving environment and landscapes in Portugal. Together they cover $75.3 \%$ of land, with natural area being also a relevant category (20.7 of the territory).

Less favoured areas represent $86.6 \%$ of the agricultural surface (PDR, p. 6). In 2005, 92.4\% of agricultural used area respected to less favoured areas, $30.2 \%$ being in mountain zones. This value is considerably higher than EU-27 average (46\%). Hence, a major part of agriculture is practiced in difficult conditions. Extensive grazing area where livestock is less than 1 livestock unit per forage hectare is $58.5 \%$ of agriculture used area and extensive arable crop area with yield below $60 \%$ of EU-27 average was $16.8 \%$ in 2007 .

Natura 2000 special protection areas and sites of community importance areas represented 10.7 and $17.4 \%$ of the territory, respectively. Under Natura area there is $18.5 \%$ of agricultural used surface and $18 \%$ of forestry area.

Strong environmental pressure is revealed by the percentage of $24.5 \%$ of samples that evidence defoliation of trees, but the estimated rate of development of $14 \%$ of this process is particularly significant in Portugal. As a positive aspect it should be indicated the average annual increase of forestry area of 40 thousand hectares between 2000 and 2005.

Agricultural production systems also have important impacts on soil and water use and quality. Irrigated area represented 12.2\% of total agricultural land used in 2007. Although this share is lower than for other EU Mediterranean countries it is expected to increase with the irrigated area of the Alqueva dam. Only $3.7 \%$ of the territory is reported as nitrate vulnerable zone and estimated surplus of nitrogen and phosphorus per hectare were 48 and $15 \mathrm{~kg}$, respectively which compared to EU-average reported values is relatively low for the first and high for the second nutrient. Estimates of soil loss due to water in areas of risk of soil erosion are above 4 tons/ha/year, significantly above EU average value.

Changes to production systems more friendly in environmental terms took place in recent years (for instance, organic farming). Average annual growth rates of utilised agricultural area under organic farming of $17.9 \%$ per year between 2003 and 2007 increased this area up to 233.5 thousand hectares which represents a share of utilised agricultural area under these systems of $6.3 \%$ of total SAU.

Agriculture also has impact on air quality. With 7638 thousand tonnes of $\mathrm{CO} 2$ equivalents, agriculture in Portugal contributed with $9.3 \%$ for total emissions, a share almost equal to $9.2 \%$ of EU-27 share in 2007. Annual decrease rate for Portuguese agricultural emissions (estimated in $2 \%$ for 2000 2007 period) is higher than average EU-27, reported as $-0.9 \%$.

Production of renewable energy from agriculture and forestry around 165 and 2808 Ktoe represent around 2 and 4.1 of total EU-27 production but increased at slow annual growth rates $(1.3 \%)$ relatively to EU-27 average increase $(4.4 \%)$. Utilised agricultural area devoted to energy and biomass production crops of 7.6 thousand hectares and its share $(0.2 \%)$ in total UAA are very low for EU-27 average standard (1.6\%).

\subsection{Diversification and quality of life in rural areas}

About $25 \%$ of Portuguese farmers in rural areas had other sources of income than agriculture in 2007. This value is lower than average share of $36.4 \%$ in EU-27. Similar pattern is found to non-agricultural (secondary and tertiary sectors) share of employment in Portugal rural areas (70.4\%) vs. EU$27(84 \%)$. Average annual growth rates of non-agricultural employment have been positive $(0.5 \%)$ but lower than EU-27 average increase of $1.3 \%$ between 2000 and 2006. The economic development of non-agricultural sectors can also be evaluated by the share of non-agricultural sector on total GVA. For rural areas of Portugal this indicator $(92.4 \%)$ is also lower than EC-27 average (95\%) and although increasing in rural areas of Portugal (1.9\% annually between 2000 and 2006) is growing faster in average terms of EU-27 rural areas $(2.5 \%)$.

Rural areas have $16.4 \%$ of Portugal's bed places installed capacity and this bed availability is decreasing (-1.8\% annual growth rate). This share is higher in average terms (26.7\%) and is increasing (1.7 annual growth rate) in EU-27.

Internet infrastructure coverage of rural areas is $86 \%$ and up-take, the percentage of population in rural areas ${ }^{5}$ having subscribed DSL internet was $5.4 \%$ in 2008. Rates of change of these indicators were 7 and $2.2 \%$ per year, respectively, between 2005 and 2008 .

Service sector accounts for $65.1 \%$ of GVA of rural areas in 2006. This share is lower than in urban areas (76.8\%). Values for these area types in Portugal are slightly above EU27 average values of 63.5 and $76.1 \%$, respectively. Annual rates of change in $\%$ of GVA in services are also higher than EU-27 and are estimated in $4.4 \%$ in the period of 2000 to 2006.

\footnotetext{
3 In European size units that measure potencial GVA.

4 Measured by GVA at basic prices per Annual Work Unit (AWU).

5 In these cases areas are rural if they have less than 100 inhabitants per $\mathrm{Km}^{2}$.
} 
The following indicators are only available with treatment at the aggregated level of NUTII. Since the unique predominantly rural area at that level of aggregation is Alentejo region of Portugal we are in fact characterizing that region from now on. However, rural inner areas of North to South would not be expected to have more favourable indicators than Alentejo.

Net migration ratio of rural areas was 3.1 per thousand in 2005 but change in that rate was negative $(-2.9 \%)$ between 2000 and 2005 . For urban areas net migration was higher $(4.2$ per thousand) and the rate of change was positive $(0.7 \%)$. Migration average values registered for EU-27 were smaller for rural areas (2.3) and larger for urban areas (4.6 per thousand) but rates were larger for both type of areas (1.2 and $6.9 \%$, respectively).

Human potential is a major factor for a country's development. It is particularly important in rural areas, usually less favoured areas that have other factors constraining development. This is a major factor that restraints Portuguese development in general and rural areas particularly. The percentage of adults with medium and superior education in rural areas was 26.7 in 2008. Average in EU-27 is $72.3 \%$. However, this is not a structural problem of rural areas as in urban areas of Portugal this percentage is only $39 \%$. This situation is changing too slowly. Rates of increase of this proportion for the country are 1.8 and $3.4 \%$ for rural areas between 2005 and 2008. Even with an average percentage much higher, for EU-27 the average rate of increase was $2.5 \%$ in the same period.

Life-long learning should bring solutions to improve human potential in Portugal. Its contribution is positive but in relative terms below EU-27 standard. The percentage of adult participating in education and training in rural areas was $4.5 \%$ in 2008 . In other areas this value goes up to $5.5 \%$. In EU-27 this percentages are $9.7 \%$ and $11.1 \%$ for rural and urban areas, respectively.

\section{Expected changes in the future agriculture sector}

In order to give the sector's increasing competitiveness and market orientation, Portuguese agriculture has received a sustained level of public support since their adhesion to the EU in January 1986. Comparing with those times, at present, both Portuguese and the CAP situation are very different. Agriculture has lost economic weight and the CAP political weight (Patier, 2000) and markets became more global and competitive. Following a course of consecutive reforms since 1992, the CAP is currently centered on three main policy axes, which aim to respectively support product prices, producer income, and structural adjustment (EU, 2009).

Before Agenda 2000 the agricultural system of EU faced an economic crisis, represented by an increasingly minor difference between the total agricultural production, expressed in economic units, and the costs, an ecological crisis, expressed in an intensified production, associated to costs more and more unlinked to nature, perceptible, for instance, on the chemical fertilization that substituted organic fertilization, and a structural crisis, expressed in production increases inhibited by quotas in several products (van der Ploeg et al., 2002). Agenda 2000 reinforced the correction of the farmers' role that began with 1992 reform, electing rural development and multifunctionality paradigm as the basis of future's CAP. The actual context of European agriculture represents the end of a cycle of agricultural modernization whit strong protection from policy and public institutions and a progressive abandonment of production structures to international markets regulation mechanisms. Without this protection, the crisis in family small scale agriculture, unable to follow behaviors dictated by modernization needs tends to be generalized also to other forms of agriculture, the attentions being now turned to demand questions, instead of supply questions, to the impact of technical models transformation and to new institutional forms of organization.

The CAP has undergone fundamental reforms over time, which demonstrates its proven capacity to respond to changing economic conditions as well as societal expectations and demands. In this process, the CAP has moved to a policy putting emphasis on market orientation and competitiveness, income support, environment, and the development of rural areas. Nevertheless, CAP is still a changing policy. The challenges ahead are driven by internal factors, such as budgetary constraints and the budget reform, with change on EU political priorities and the loss of the traditional agriculture importance, and also by external factors, such as globalization and the world financial crisis. CAP challenge will be to develop an European agri-food market that can survive in a world competitive market and answers the WTO pressures, respecting the budget, stimulating the agricultural sector competitiveness and promoting products' quality and the respect by environmental concerns and animal welfare. Finally, CAP must ensure a sustainable use of natural resources and an effective rural development.

The evolution will surely continue to be from a sectoral to a territorial approach, slowly re-balancing its two pillars. We can expect Portuguese agriculture to slowly adjust itself to the policy changes with adjustments on agricultural product composition accommodating the reform effects and adjust to a new framework without sudden brakes or disclosers (Jorge, et al., in print).

According with the information on farmers' expectations (Rosário, 2005), obtained through direct and personal interviews to 928 farmers within the Farm Accountancy Data Network (FADN, ) results revealed no great farmers motivation to introduce changes in their production systems in the short $(79.3 \%)$, or medium term $(73.0 \%)$, a situation similar to that of the previous years. Intentions to change the current production system corresponded to only $21 \%$ of the interviews. In the medium term, this expectation decreases to $18.5 \%$ for active situations. Approximately $79 \%$ of the farmers do not intend to complement their farm income with 
income from other sources. Only $20 \%$ of the farmers are willing to resort to off-farm income sources and $5 \%$ of the contacted farmers consider developing supplementary income sources within the farm. The difficulties resulting from the Global Economic Framework for the farming activity were the most often referred by the interviews (56\%) followed at a distance (15\%) by Farms' Structural Hindrances (Rosário, 2005).

Rural development, I\&D, market regulation and price stabilization are the keys for Portuguese agriculture sector restructuration, but also to encourage diversification and innovation in rural areas. In the next decades, Portuguese agriculture will be faced with the global challenge trade-off of food security and safety (increasing production volumes and reduce external dependence and deficit) and environmental safety (combat climate change and improve natural resources sustainability, biodiversity and landscape preservation). This implies creating conditions for Portuguese agriculture to produce enough food based on environmental, quality and animal welfare's friendly technologies and on competitive market conditions. It also involves the production of rural public goods that contribute to the natural resources preservation and combating climate change, abandon and human desertification. In synthesis, it means improving the quality of life in rural areas based on consolidation and diversification of the economic and business environment (Avillez, 2010).

\section{Possible Future Multifuntionality Issues}

\subsection{Food security, food safety and quality}

Food security, food safety and quality must be ensured throughout the Portuguese food chain as one of its foremost roles. Latest developments have shown that these issues are not to be neglected and may be accentuated by climate change, by increased water scarcity, by food scandals or crises or by an inadequate or inefficient food chain. The ability to react to these issues depends on agricultural sector performance, competence to maintain sustainable modes of production and consumption linking economic growth and environmental objectives with a steady scheme of trade relationships.

The farmers' difficult task is to supply food in an open and increasing competitive market which supposes both: to produce at competitive prices and to fulfill societal desires and expectations regarding high levels of food, product quality and standards of food safety, animal welfare and environmental friendly farming systems. Relating the Portuguese external trade, namely the exports/imports rate (about 35\% in 1998) and the degree of self-sufficiency $(87 \%$ in 1999), the numbers show a negative situation in most of agricultural products. For consumers, the analysis highlights significant benefits related with the growth, diversity and quality enhancement of food supply. Moreover, consumers have benefited from the evolution of agricultural prices less than proportional to the production level reductions, which were partly appropriated by the processing circuits and distribution stakeholders. The benefits to consumers result evident since accession by the fact that the Portuguese general annual price evolution has been systematically higher than the specific evolution of food prices which significantly contributed to the domestic inflation control. Meantime, the negligible development in agricultural production volume associated with a sharp augment in food consumption and increased integration in European markets led Portuguese agricultural and food products' foreign trade to progress in a very unfavorable way (Pinto, 2000). The deficit doubled in approximately one decade till the year 2000 and still rising. Most Portuguese imports come from the EU countries of Spain, Germany, France, Italy and the United Kingdom. Most exports also go to other EU member states.

Portuguese wine and olive oil are especially praised by nationals for their quality, thus external competition (even at much lower prices) has had little effect on consumer demand. Portugal is a traditional wine grower, and has exported its wines since the dawn of western civilization: Porto wine, Vinho Verde and Madeira Wine are the leading wine exporters. Portugal is also a quality producer of fruits, namely the Algarve oranges, Cherries from the center east countryside and pera rocha (a specific Portuguese type of pear). Other exports include horticulture and floriculture products, beet sugar, sunflower oil, cork and tobacco. Portugal produces half of the world's cork.

In terms of safety, the European food market in general and the Portuguese market in particular have suffered from several food scares of which BSE and nitrofuranes scandals are good examples. Under the glare of intensive media attention, specific consumer food safety concerns can erupt into widespread alarm. Consumers are therefore more and more concerned about food safety and quality, more skeptical about food supply, desiring more transparency in production and distribution channels and, for some products, also more skeptical about the production process. Depending on their perceptions of the risks associated with the product, food scandals led the individual consumers to react in different ways (Henson and Northen, 2000).

According Lucas and Toscano (2003) Portuguese consumers doesn't thrust about food handle in restaurants and they consider having little information to judge correctly the safety level of a product. Specifically, they consider food not as healthy as it should be; they need more nutritional information as they don't find it on food label. In the consumers' attitudes to food price, a clearly disstisfaction of respondents is the main result. In their opinion a decrease in food price can induce a well balance diet. In relation to the impact of food production processes on environment, consumers are very concerned and they consider the ordinary production system aggressive to the environment. Consumer food confidence is higher in fresh fruit and fresh vegetables, fish, dairy-food, rice, pasta, wine and olive oil then in meat, crayfish, prepared dishes, eggs and mayonnaise. They have 
also higher confidence level on food prepared and cooked at home and lower confidence level in crude meat, food with residues of permitted pesticides and fruits and vegetables with artificial colorants. Portuguese consumers read label information frequently and the date of caducity is the information more consulted by the consumers, leaving off other important food safety information and the relation between diet and health, such as the instructions of storage and cooking, the nutritional value and the ingredients. Veracity, content, and product quality association, are label information perceive as truthful.

Because safety and health related issues influence consumers' attitudes and behaviour (Lucas, 2006), food safety and freshness are determinant in defining food experienced quality. In an empirical research with beef consumers, Marreiros (2005) found that freshness and butcher's advice are very important cues for meat buying-decision. Colour is the other main cue for choosing meat. The importance of fat as an attribute for experienced meat quality and as a choice cue is not confirmed in the study, and consumers' awareness and knowledge about the quality labels and about the PDO meat brands was found to be rather low. On the other hand Lucas (2006) concluded that these guarantees or certifying labels are valuable decision-making criteria for some Mediterranean consumers segments (Lucas, 2006). The country-of-origin or region-of-origin of meat are products attributes with complex effects on consumer behaviour as they have high symbolic meaning, reflecting geographical differences in the food culture, both between and within countries.

\subsection{Land Management}

Although the farming past has shaped the rural character, often the specific farming practices that helped generating those features lost their competitiveness. In some areas, notably those with a low productivity of soils or economically unfavorable structures, agricultural activities and land management as such are at risk. The disappearance of farming results in losing the associated environmental and cultural assets, such as typical landscapes and valuable habitats. Those assets have the characteristics of public goods, because the demand and supply cannot be satisfied through market mechanisms. Besides its traditional function of producing food, agriculture has a determinant role in the maintenance and evolution of rural characteristic landscapes and in environmental and biodiversity preservation. Policy measures are needed for ensuring delivery of these goods. However, public goods cannot be delivered without the necessary farming capacity being in place - "public money for public goods" can only be delivered where there is an agricultural presence to which this condition can be attached.

One of the key issues of land management is the possible abandonment of rural areas in a near future. The trends after 2013 (Jorge, et al., in print) point to diverse effect depending on the Portuguese regions. The North and Lisboa, with production systems more difficult to extensify, are those who demonstrate a greater abandonment potential.

\subsection{Viable Rural Areas}

As looks upon the economic would-be of rural areas, agriculture offers a stand for economic diversification in rural areas. The multiplicity of activities not only allocates agricultural systems continuity but generate employment and supplementary profits in specific regions. In spite of the decline in the relative economic weight of the primary agricultural sector, rural tourism economic role remains significant, particularly in remote Portuguese areas where agriculture as such has a significant share in employment. In this context, the development of sustainable tourism is of special importance. Many of possible future projects should support the creation of small-scale infrastructure, of recreational infrastructure offering access to natural areas and the development of tourism services relating to rural tourism. However, the rural tourism option should be integrated in the specific regional contexts in order to multiply effects on economy and society that interact with other farm activities and sharing territory. Being a cross- activity, the rural tourism sustainability depends more on establishing relationships (local people, business, tourists, senior administrators) than a monocultural specialization of imported models. The option should always attend the rural tourism decision-making based on opportunity costs comparing with other possible solutions. It should not be a direct consequence of the absence of other options or the apparent attractiveness of foreign models which opportunities are cyclical. The strategy and actions should be based on horizontal and vertical structure of production, where rural tourism is integrated in space and time with other activities and sectors.

In the context of viable rural areas, innovation plays a crucial role. An activity as agriculture where the flows are increasingly globalized but paradoxically the success of many products depends on the maintenance and valuation of its regional identity, innovation is the guarantor of the constant product renewal due to changing demand profiles. It is the innovation that can induce the ability to create products and services themselves, supplementing them with innovative management, able to enter into these specific value-added chains for the benefit of the region. It supposes a process where horizontal integration is necessary but where integration vertical also should occupy a privileged place in developing strategies and future actions. In addition to the operational measures aimed to strength the productive base, the range of agricultural production is the one that requires innovative procedures: (a) based on quality demand that combine tangible and intangible factors (skills and human resources), (b) develop relational capital (public / private interaction, formation of integrated regional clusters) and (c) target the needs of technology support and enjoy the externalities offered by the consequent development.

The contribution of agricultural Portuguese regions to the economic progress implies also the existence of other attributes such as infrastructure and services which plays important tasks for farmers, for tourists, visitors and other inhabitants of rural areas. Beyond innovation, information and 
communication technologies (ICT) and I\&D dissemination must play their important role. They make easier connections between rural and urban regions and facilitate employment creation and diversification possibilities inside rural areas. Both, growing internet infrastructure coverage of rural areas and increasing the percentage of population in rural areas having subscribed DSL internet was good indicators. Quality of life of rural population depends by and large of the maintaining of rural area economic development which is close linked with the access to services of general interest. Development can help to promote competitiveness in the agricultural and food processing sectors.

Safety and national defense are public goods when the depopulation problem is focalized because national cohesion (in economic, social and territorial terms) is compromised. To avoid abandon and depopulation of rural zones and consequently inverse concentration in urban centres, agricultural landscape has to preserve their appeal for citizens. Inverse the rural population exodus and promote their return depend intimately of rural attractiveness potential which strongly depends of it capacities to catch new investments, create new employments and promote parity of economic and social opportunities. From the specific measures for regions with high risk of abandonment, it is noted the importance of strengthening and / or adaptation in Portugal of a few already in force, such as income support and early retirement which should aim major rejuvenation of farmers and the resizing of the holdings. Because its direct impact on national security, measures devoted to the vulnerabilities of forest and the combat to forest fires are also of vital importance to the country (Fernandes, 2005).

The origin or local provenance should have a growing role, promoting the endogenous development potential of the territory, which passes through the local regeneration with priority mobilization of local actors in the management of local interests, creation of local decision-making centers and oriented economic recovery of endogenous resources. These features enhance and support a diversity of solutions, ranging from agriculture component in the form of traditional high quality products, protected designations of origin (PDO), new crop profitably market (hydroponic and organic), nonagricultural land within the multifunctionality of agriculture as rural tourism mentioned before and other activities such as recreation, crafts, preservation of cultural heritage, including the rural amenities (immaterial tradable goods) as the scenery, the pure water, biodiversity and climate.

It should be noted that support non agricultural activities serves both, supply and demand sides. Considering the consistent increase number of consumers, especially from urban zones, which manifest willingness to access and enjoy such goods, this represents an expanding market.

\subsection{Competitiveness in Global Markets}

Portugal is a high income mixed economy which occupied the 43rd position out of 134 countries and territories in the Global Competitiveness Report from World
Economic Forum (Schwab, 2009). Comparing with 2005 where Portugal placed on the 22nd position this showed that the country had dropped twenty one places regarding the actual ranking position. The report "assesses the ability of countries to provide high levels of prosperity to their citizens". This in turn depends on how productively a country uses available resources. Therefore, the Global Competitiveness Index measures the set of institutions, policies, and factors that set the sustainable current and medium-term levels of economic prosperity (World Economic Forum, 2009).

Some domestic problems with strong impact on the economy and consequently on country competiveness are possible to identify. Like in other countries with very hot summers and seasonal drying of soils and vegetation, every year large areas of the Portuguese forest are destroyed. This situation has strong economy impact because many people and industries depend on forestry related activities and as well a significant ecological impact associated with a safety issue for the populations. Other problem that commits agriculture competitiveness is the public debt which exceeds $60 \%$ of GDP. This problem, in addition with the overdimensioned public sector, is a threat to the Portuguese economy and the State's financial sustainability.

As previously mentioned, one of the prevalent aspects of Portuguese agriculture is the dominance of production system with dependence on supports and subsidies. Thus, the search for economically viable alternatives involves a process of technical and structural conversion. On the other hand, some effective conversion measures represent an increased risk of abandonment and human desertification. According to Avillez (2010), it is desirable in the future to have in Portugal the following variety of agricultural systems: 1) agro-environmental systems socially sustainable and target for conservation of nature, biodiversity and territorial land management; 2) agro-commercial systems socially sustainable and target for organic and bio-energy production; and 3) agro-commercial systems economically competitive such as vineyards, olive trees, horticulture and quality meat production systems.

The Portuguese farmers will have to face global markets challenges at the same time as they have to value high standards coming from environmental, animal welfare, quality and food safety goals. According natural and structural specificities an adequate response for Portuguese agricultural sector to these challenges will be to ensure increased product and process quality.

\subsection{Responding to climate change}

As been seen before, CAP has been profoundly reformed in the recent past $(\mathrm{EC}, 2003)$ - the role of intervention mechanisms has been significantly reduced, the support is mainly decoupled and subject to conditionality and there has been a reinforcement of Rural Development (CAP 2nd pillar). Additionally, the policy tends also to be more efficient, meaning that the market disequilibrium and public stocks are not so common any more, there has been a raise on 
the competitiveness and a change in the agriculture's role on commercial exchanges and there has been a better use of public funds with more efficient income transference.

One issue that is now in the "concerns table" is how to face the new challenges, from climatic changes to hydric resources and biodiversity protection. Simulations made for Portuguese agriculture (Jorge et al, in print) point to a general positive result of the future CAP, due to a predictable decrease on animal production activities and forage production extensification - this will lead to a decrease on negative environmental externalities, not due to a reduction on seeded area but to a change on the land cover diversity and its extensification. Additionally, there will be reductions on potential lixiviation, on $\mathrm{CH}_{4}$ and $\mathrm{NO}_{2}$ emissions and on the Global Warming Potential (GWP).

Nevertheless, some authors (Rosário, 2003) states that agri-environmental measures are not completely recognized by farmers as public support to change practices, as they are still mainly comprised as just subsidies for agriculture and income for farmer and there are still many farmers that don't intend to apply for this support. The same author (Rosário, 2003) recommend a bigger effort on environmental education of farmers, on information availability and on environmental training actions, in what concerns amenities, residues and resources as the farmer is the privileged actor that contacts in a constant and professional way with all these situations.

\section{Conclusion}

A considerable part of Portugal is dedicated to agriculture, although it does not represent most of the economy. Nevertheless, the sector has a crucial importance on the maintenance of national cohesion in economic, social and territorial terms and so an effort must be done to revitalize it.

This effort must accomplish all different agriculture's roles: the main vectors of development must be put in human resources - to train, qualify and rejuvenate human resources -, in the diversification of production basis - new technologies, new products -, in supporting (as a public good) the multifunctionality of agriculture - new rural activities, like tourism, gastronomy, landscape -, and finally in correcting the infrastructural constraints. This could reduce the economic dependence of Portuguese agriculture and its vulnerability to EU support mechanisms and reverse the rural population exodus, creating conditions to raise rural attractiveness.

The evaluation of the potential of agriculture and natural resources capacities in each region can't separate itself from the capabilities generated by farms and from the infrastructural and environmental constraints and spaces where they operate. When the main point is the global competitiveness, innovative capabilities of a country or region depend mostly on the sector dynamics and they remain spatially related to regions, cultures and networks (formal and informal) carrying different conditions to promote endogenous dynamics innovation.

\section{References}

Avillez, Francisco (2010), "As políticas públicas de apoio à agricultura na UE. Que futruro?", Apresentação na sessão comemorativa do $20^{\circ}$ aniversário da Agrogés, 21 Janeiro, http://www.agroges.pt, Retrieved February 2010.

EC- European Commission (2003), Mid-Term Review of the Common Agricultural Policy: July 2002 Proposals, Impact Analysis, Brussels http://europa.eu.int/comm/agriculture/publi/ reports/mtrimpact/rep en.pdf, Retrieved March 2009.

EC - European Comission (2009), "Why do we need a Common Agricultural Policy? Discussion paper by Director-General Agriculture and Rural Development ", December, 16 pp, Brussels.

Fernandes, Maria João P. (2005), "Abandono agrícola: um problema de segurança e defesa nacionais", Série Estudos e Documentos, Documento $\mathrm{n}^{\circ} 11$, GPPAA - Gabinete de Planeamento e Política Agro-Alimentar, Ministério da Agricultura, do Desenvolvimento Rural e das Pescas, Lisboa, Portugal.

Henson, S. and Northen, J., (2000). "Consumer assessment of the safety of beef at the point of purchase: A pan-european study." Journal of Agricultural Economics, 51 (1), 90-105.

Jorge, Raul, P. Esperança, M.B. Martins, M.R. Lucas "Medium Term Prospects for Portuguese Agriculture under Health Check Proposals - A Quantitative Analysis with the CAPRI Modelling System, New Medit, in print.

Lucas, M. Raquel e R. Toscano (2003). "Segurança alimentar e comportamento do consumidor em Portugal", XIII Portuguese Congress of Animal Science - Producing with quality and safety", Evora, Portugal, October 1-4.

Lucas, Maria Raquel, Handbook of Consumer Behaviour (2006), Leonardo da Vinci project (PL/04/B/F/PP-174 455).

Marreiros, Cristina (2005), “Consumers' Perceptions of and Attitudes to beef: a study of labelled beef in Portugal", $\mathrm{PhD}$ Thesis, Newcastle-upon-Tyne, UK.

OCDE-FAO (2009), "Agricultural outlook", http://www.agrioutlook.org, Retrieved 2010-02-03.

Patier, Eduardo D. (2000), "Experience of accession to the EU. Sapian and Portugal ", in Agricultural Policy and Enlargement of the European Union, edited by Alison Burrell and Arie Oskam, Wageningen Pers, The Netherlands, p. 131-142.

Pinto, A. Sevinate (2000), "A Integração Europeia da Agricultura Portuguesa", http://www.agroges.pt, Retrieved 2010-02-12.

Rosário, Maria do Socorro (2003), "Sensibilidade dos Produtores Agrícolas face ao Ambiente", Estudo n. ${ }^{\circ}$ 7, Série Estudos e Documentos, Gabinete de Planeamento e Políticas, Ministério da Agricultura do Desenvolvimento Rural e das Pescas.

Rosário, Maria do Socorro (2005), "Expectativas dos empresários agrícolas - Informação Produzida a partir de um Painel Experimental de Produtores", GPPAA - Gabinete de Planeamento e Política Agro-Alimentar, DSEGI - Direcção de Serviços de Estatística e Gestão de Informação, Lisboa, Portugal.

Schwab, Klaus (2009), "The Competitiveness Report 2009-2010", World Economic Forum, Geneva, Switzerland. http://www.weforum. org/pdf/GCR09/GCR20092010fullreport.pdf. Retrieved 2009-09-12.

Van der Ploeg, J. D., Long, A. \& Banks, J. (2002), "Living Countrysides - Rural Development Processes in Europe: the State of the Art”. Elsevier bedrijfsinformatie, Doetinchem, NL.

World Economic Forum (2009), "The Global Competitiveness Index rankings", http://www.weforum.org/pdf/gcr/2008/rankings.pdf, Retrieved 2009-09-12. 